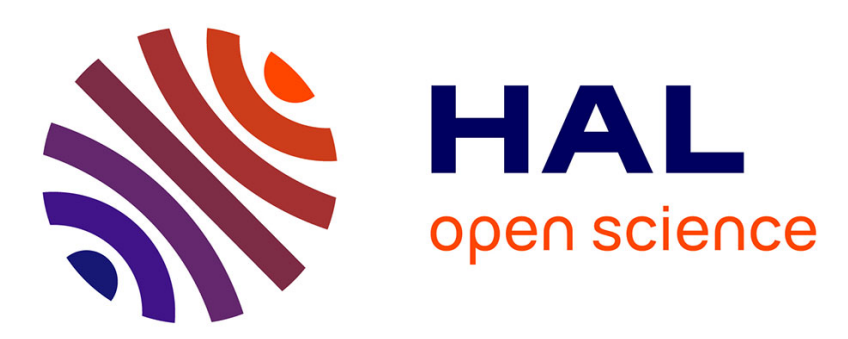

\title{
In Situ EXAFS Characterisation of the Synthesis of Polynuclear Chloroniobates from Sm Atom Reactions with Niobium Pentachloride
}

C. den Auwer, M. Andrews, V. Briois, C. Cartier Dit Moulin, H. Dexpert

\section{- To cite this version:}

C. den Auwer, M. Andrews, V. Briois, C. Cartier Dit Moulin, H. Dexpert. In Situ EXAFS Characterisation of the Synthesis of Polynuclear Chloroniobates from Sm Atom Reactions with Niobium Pentachloride. Journal de Physique IV Proceedings, 1997, 7 (C2), pp.C3-1051-C3-1056. 10.1051/jp4:19972135 . jpa-00255196

\section{HAL Id: jpa-00255196 https://hal.science/jpa-00255196}

Submitted on 1 Jan 1997

HAL is a multi-disciplinary open access archive for the deposit and dissemination of scientific research documents, whether they are published or not. The documents may come from teaching and research institutions in France or abroad, or from public or private research centers.
L'archive ouverte pluridisciplinaire HAL, est destinée au dépôt et à la diffusion de documents scientifiques de niveau recherche, publiés ou non, émanant des établissements d'enseignement et de recherche français ou étrangers, des laboratoires publics ou privés. 


\title{
In Situ EXAFS Characterisation of the Synthesis of Polynuclear Chloroniobates from Sm Atom Reactions with Niobium Pentachloride
}

\author{
C. Den Auwer*******, M. P. Andrews*, V. Briois**, C. Cartier dit Moulin** and H. Dexpert** \\ * Department of Chemistry, McGill University, Montreal Québec H3A 2K6, Canada \\ ** LURE, Université Paris Sud, 91405 Orsay Cedex, France \\ *** CEA ValRhô, DCC/DRDD/SEMP, 30207 Bagnols sur Cèze, France
}

\begin{abstract}
A new method to prepare solid state chlorometallates by reductive dechlorination of solvated niobium pentachloride with vaporisation of nominally free atoms of samarium is described. Products were prepared in an original set-up by evaporation of samarium into a mixed toluene solution of $\mathrm{NbCl}_{5}$, at $180 \mathrm{~K}$. The local order around the $\mathrm{Nb}$ atoms was probed by EXAFS spectroscopy at the Nb K edge, using an in situ cryostat coupled to the metal vapour oven, in order to better understand the condensation mechanisms. These in situ measurements confirm our previous ex situ EXAFS studies with solid state products obtained by $\mathrm{Sm}$ vaporisation: condensation of $\mathrm{NbCl}_{5}$ by face-sharing octahedra.
\end{abstract}

\section{INTRODUCTION}

The introduction of so-called "soft chemistry" or low temperature methods for making solid state materials from molecular precursors offers potential access to mechanistic details of assembly by chemical and spectroscopic interception and interrogation. Our method differs from traditional high temperature solid state synthesis in that rare earth atoms are deposited into low temperature solution of dissolved $\mathrm{NbCl}_{5}$ starting materials. This method to condense $\mathrm{NbCl}_{5}$ into chains by reaction with vaporised atoms of samarium and erbium has been described in previous studies $[1,2]$. We observed the evolution of the cluster structures upon vaporisation time and have identified the dependence of the final niobium halide cluster structure on the choice of the vaporised rare earth atom and discussed two possible condensation routes. Ab initio EXAFS calculations based on two condensation models of $\mathrm{NbCl}_{5}$, compared with experimental EXAFS spectra, figured prominently among the characterisation tools to ex situ investigate the solid state products. As shown in Figure 1 we identified Er vaporisation to an edge sharing octahedra condensation and $\mathrm{Sm}$ vaporisation to a face sharing octahedra condensation.

In this paper, we describe a matrix isolation set-up allowing an in situ EXAFS characterisation of $\mathrm{NbCl}_{5}$ elaborated into chains by reaction with vaporised samarium atoms. The scope of such developments for in situ characterisation is two-fold: i) because the chemical system involved (i.e. $\mathrm{NbCl}_{5} /$ rare earth) is very fragile (oxygen and water sensitivity) the in situ set-up is the only way to avoid alteration of the reaction products and thus enables us to confirm our previous findings; ii) because our previous results are based on ex situ study of sampled products during the reaction process, it was not possible to observe the earlier stages of the reaction where additional information on the reaction condensation process may be extracted.

In the first part of this paper we describe the design of our adapted in situ Metal Vapour Synthesis (MVS) [3, 4] reactor for the absorption measurements. In the second part, results are compared to our previous findings and a quantitative EXAFS analysis is presented.

\section{THE IN SITU REACTOR SET-UP}

\subsection{Experimental Set-Up}

The reactor was conceived to mimic the two major features of the large Metal Vapour Synthesis apparatus used in our previous works $[1,2]$ : vacuum metal atom source (furnace), and low temperature fluid phase solution reaction zone.

The apparatus shown schematically in Figure 2 consists of a reactor module (cryostat + oven), a compressor (for the variable temperature helium cryostat CSW 202 ADP cryogenics), a power supply (to heat the knudsen cell of the furnace) and a diffusion pump (to ensure a vacuum of about $10^{-5} \mathrm{~mm} \mathrm{Hg}$ in the reactor). The shroud houses a cryostat head on which a temperature controlled optical window (between 130 and $180 \mathrm{~K}$ ) is provided as the substrate to hold a pool of toluene containing dissolved $\mathrm{NbCl}_{5}$.

The external stainless steel shroud is connected both to the oven and to the diffusion pump. It surrounds the cryostat tip that supports the reaction window. This window can be rotated around the cold finger axis to position it either horizontal (vaporisation position) or vertical perpendicular to the $\mathrm{X}$-ray beam (data acquisition position). The $1 \mathrm{~mm}$ thick quarz window is compression-fitted in a copper holder and good thermal contact was achieved with indium foil gaskets.

The furnace was made of a double wall concentric brass cylinders welded together and thus creating a chamber for circulating cold water for cooling purposes. Two electrodes, at the centre position, are connected to the power supply via a rheostat to control the vaporisation flux. A tantalum knudsen cell is fixed to the end of the electrodes and contains the 
samarium. Finally, two radiation shields are placed in front of the knudsen cell to avoid radiation damage to the target solution on the window. Above the cell, a quartz oscillator mass balance is mounted to monitor the vaporisation rate.

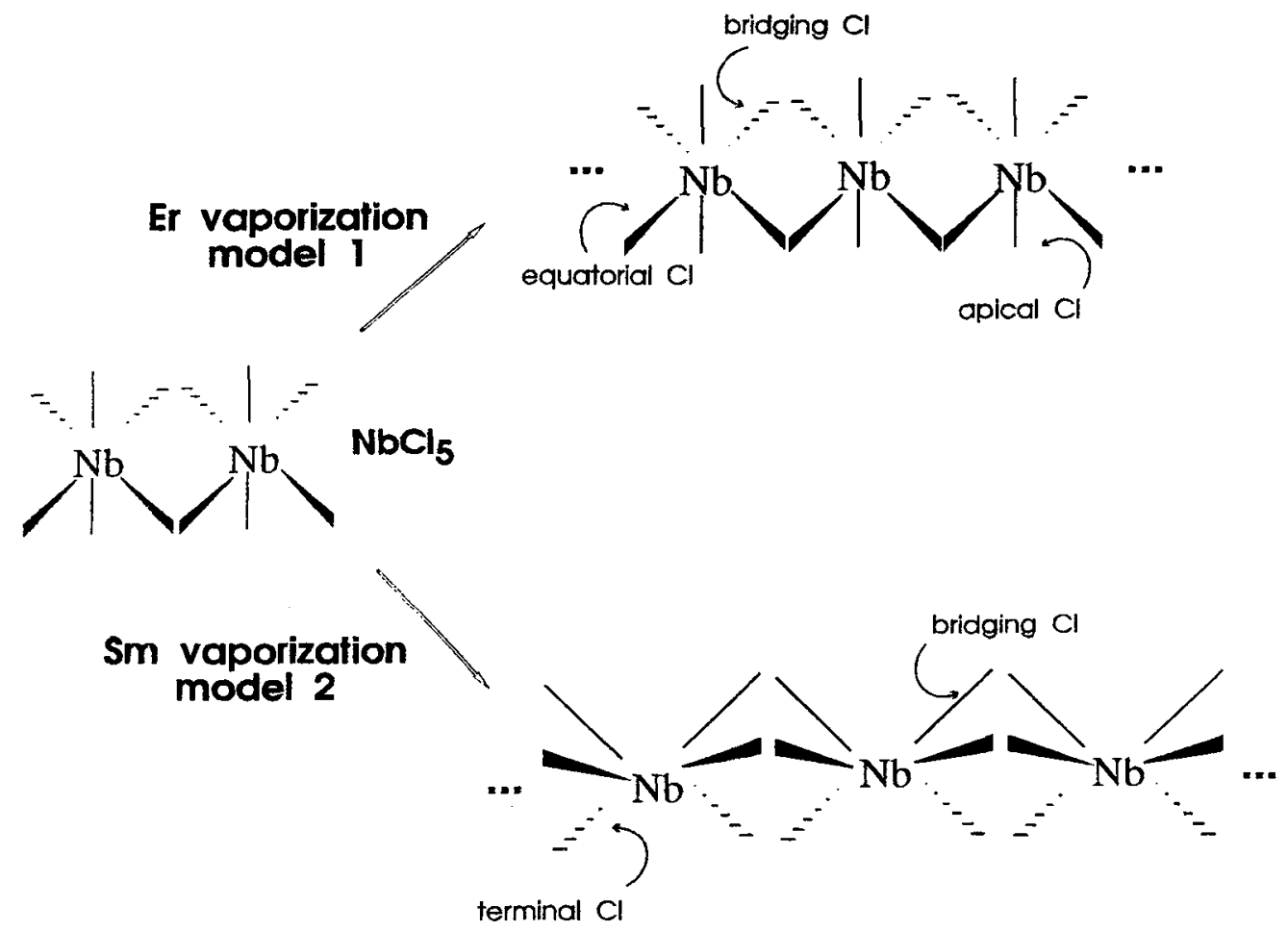

Figure 1: Two condensation routes of $\mathrm{NbCl}_{5}$ cluster upon rare earth vaporisation [2].

\subsection{Atom Synthesis and In Situ X-Ray Absorption Measurements}

Manipulations of all air sensitive compounds and starting materials were carried out under argon in a dry box.

Data were collected at $130 \mathrm{~K}$ on beam-line D42 of the DCI $1.8 \mathrm{GeV}$ synchrotron light source (LURE, Orsay, France) at the $\mathrm{Nb} \mathrm{K}$ edge (18986 eV). A channel cut $\mathrm{Si} 331$ monochromator was used. Spectra were taken in transmission mode using argon filled ionisation chamber detectors. Energy calibration of the monochromator was carried out at the $\mathrm{K}$ edge of $\mathrm{Zr}$ metal $(17998 \mathrm{eV})$. Energy resolution at $19000 \mathrm{eV}$ was $9.7 \mathrm{eV}$. Figure 3 shows a picture of our experimental set-up.

The MVS device was evacuated to about $10^{-4} \mathrm{~mm} \mathrm{Hg} .2 .5 \mathrm{ml}$ of saturated $\mathrm{NbCl}_{\mathrm{s}}$ in toluene were injected onto the quartz window. About $12 \mathrm{mg}$ of samarium were vaporised during each 30 minute vaporisation cycle. Syntheses and in situ measurements were performed the following way:

The quartz window temperature is set to $180 \mathrm{~K}$. At this temperature, the vapour pressure of toluene is about $10^{-5} \mathrm{~mm} \mathrm{Hg}$. The window is positioned horizontally and the injection septum rotated to the apical position above the window. $\mathrm{The}^{\mathrm{NbCl}} \mathrm{S}_{5}$ deep red solution is then carefully injected with an anaerobic syringe (Pressure-Lok syringe, Precision Sampling Corp). The quartz window temperature is then lowered to $130 \mathrm{~K}$ to freeze the solution and the window could then be rotated normal to the $\mathrm{X}$-ray beam for acquisition of an X-ray absorption spectrum of the stock Sm free solution, named CYCLEO.

It is again positioned horizontally for evaporation of samarium atoms into the solution. The temperature is set at $180 \mathrm{~K}$ again to liquefy the toluene. A small stirring bar, placed on the window, allows mixing of the solution during the metal vaporisation. The metal flux is monitored by the quartz mass balance. During the vaporisation, the deep red $\mathrm{NbCl}_{5} \mathrm{Sm}$ free solution turns progressively brown. At the end of the vaporisation time, the oven is turned off and the quartz window cooled down again and turned vertically to allow data acquisition. Many vaporisation / data acquisition cycles are performed over a period typically of 10 hours.

Cycles are identified in the text with cumulative vaporisation time, each cycle corresponding to 30 minutes of vaporisation: CYCLE0 for 0 minute vaporisation (unreacted $\mathrm{NbCl}_{5}$ ) CYCLE1 for 30 minutes vaporisation, CYCLE2 for 60 minutes vaporisation and CYCLE3 for 90 minutes vaporisation. 


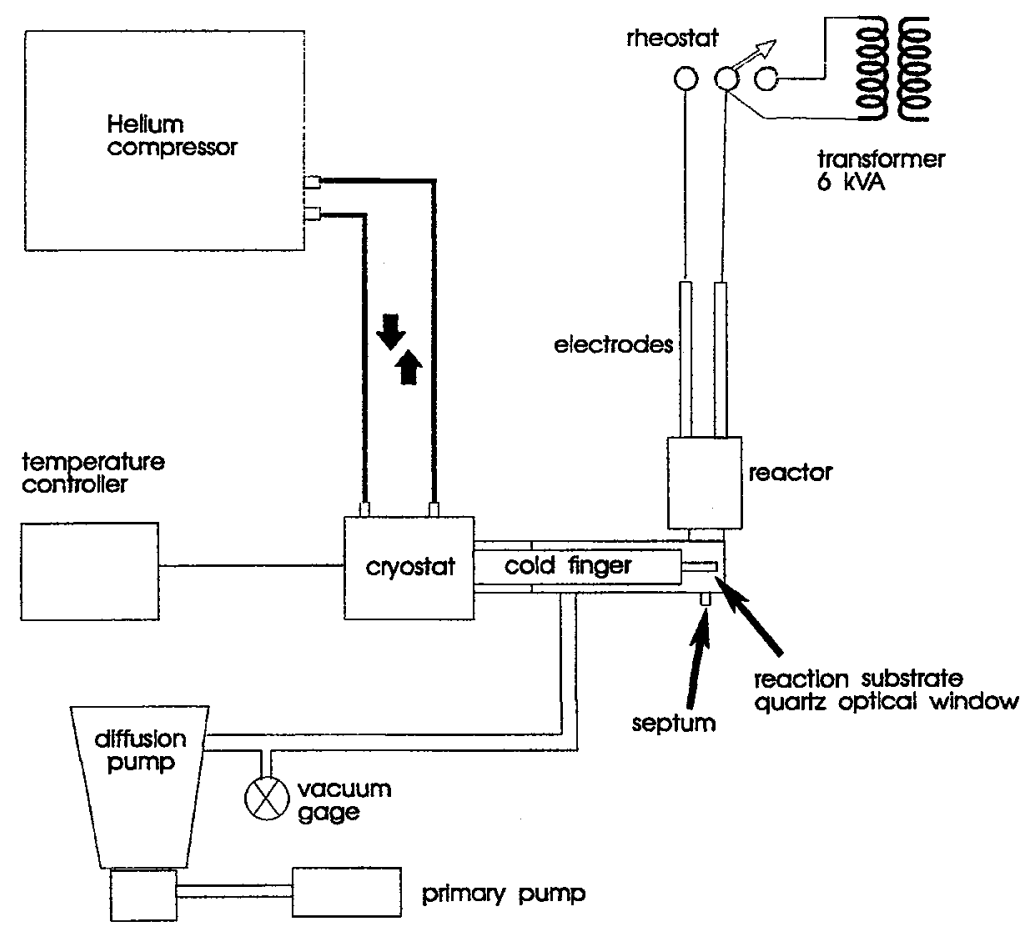

Figure 2: MVS reactor set-up for in situ EXAFS studies.

\subsection{Data Treatment}

EXAFS analysis was performed with the codes "EXAFS pour le Mac" [5]. Phases and amplitudes were extracted from the simulation of $\mathrm{NbCl}_{5}$ with FEFF6 code in such a way that has been fully described in our previous studies $[1,2]$.

EXAFS oscillations related to the chlorine contributions of the reaction medium were adjusted with 4 chlorine shells. Among them, 2 shells (with no variable parameters) correspond to parameters of $\mathrm{NbCl}_{5}$ in solution (i.e. those that have been determined when adjusting CYCLE0) and 2 shells (with adjusted parameters) correspond to the products (i.e. 2 shells of $\mathrm{Nb}-\mathrm{Cl}$ ). The coordination of niobium chlorides is typically 6 for these high oxidation states and therefore the sum of the number of neighbours over the 4 shells has been set to 6 . For unreacted $\mathrm{NbCl}_{5}$ product, the chlorine coordination numbers follows the relation $\mathrm{N}_{3}$ (terminal) $=2 \mathrm{~N}_{4}$ (bridging). Upon vaporisation, the values found for CYCLE0 $\left(\mathrm{N}_{3}=4, \mathrm{~N}_{4}=2\right)$ are decreasing, due to the product formation. Concomitantly, the coordination numbers related to the product ( $\mathrm{N}_{1}$ for terminal $\mathrm{Cl}_{\text {and }} \mathrm{N}_{2}$ for bridging $\mathrm{Cl}$ ) increase. The percentage of product in the reaction medium can then be evaluated by the number $\eta=\frac{\mathbf{N}_{1}+\mathrm{N}_{2}}{6} 100$. This method is however not able to give a precise value of $\eta$. It can only confirm the decrease of the $\mathrm{NbCl}_{5}$ concentration with the number of vaporisation cycles.

\section{RESULTS AND DISCUSSION}

The moduli of the Fourier transformed (FT) EXAFS spectra of i) the starting solution CYCLE0 and ii) the reaction medium after $\mathrm{Sm}$ vaporisation are compared to the solid state $\mathrm{NbCl}_{5}$ reference compound (at $77 \mathrm{~K}$ ) in Figure $4 \mathrm{a}$. The major contribution $\mathrm{A}$ is due to $\mathrm{Cl}$ contributions whereas for $\mathrm{NbCl}_{5}$ and CYCLE0 contribution $\mathrm{B}$ due to $\mathrm{Nb}$ neighbour is very weak because $\mathrm{NbCl}_{5}$ is a dimer with a large distance between the two $\mathrm{Nb}$ atoms (3.99 $\AA$ in $\mathrm{NbCl}_{5}$ [6]). Note that these contributions account for both unreacted $\mathrm{NbCl}_{5}$ and product formation. As expected, there are no major differences between the FT of solid state $\mathrm{NbCl}_{5}$ and the FT of CYCLE0, showing also that sample homogeneity is adequate with this in situ set-up. This is confirmed by the best least square fitting parameters determined for CYCLEO (Tab. I) which agree well with the crystallographic parameters of $\mathrm{NbCl}_{5}$. Given the weakness of contribution B, it could not be quantified and we consider here only changes on contribution A, occurring upon vaporisation. For CYCLE1,2,3, contribution $\mathrm{A}$, related to the $\mathrm{Cl}$ backscatters, is structured into two components: peak A2' and shoulder A1' on the left side of A2' (these notations refer to our previous work [2]). Main peak A2' is shifted towards larger distances on going from CYCLE1 to CYCLE3. These differences between the main contribution A of 
the Fourier transform reflect the structural evolution of starting $\mathrm{NbCl}_{5}$ dimer. These vaporisation time dependent features have already been observed with our ex situ products obtained by Sm vaporisation. However, the amount of samarium deposited here is much smaller $(12 \mathrm{mg} / 30 \mathrm{~min}$ ) than the amount deposited in our ex situ MVS reactor $(180 \mathrm{mg} / 30 \mathrm{~min})$. This suggests that we are looking now at the early stages of the condensation process. Simulation with FEFF6 of trimer, tetramer and pentamer clusters according to models 1 and 2 ( $c f$. Fig. 1) allowed us to attribute $\mathrm{Sm}$ vaporisation to model 2 condensation [1, 2]. Structural parameters of the products, deduced from the fit of the EXAFS oscillations of the reaction medium (product + unreacted $\mathrm{NbCl}_{5}$ ), are given in Table I. Fits of the filtered $\mathrm{Nb}-\mathrm{Cl}$ EXAFS oscillations of the reaction medium as well as fit of the corresponding filtered FT are shown in Figure $4 \mathrm{bc}$. Model 2 condensation predicts, for an infinite chain, a decrease to 0 of the number of terminal $\mathrm{Cl}$ and an increase to 6 of the number of bridging $\mathrm{Cl}$. Decrease of the number of terminal $\mathrm{Cl}$ from 2.5 for CYCLE1 to 1.8 for CYCLE3 and increase of the number of bridging $\mathrm{Cl}$ from 3.5 to 4.2 confirms that $\mathrm{NbCl}_{5}$ condenses into model 2 linear chains upon $\mathrm{Sm}$ vaporisation. Even if these numbers bear a large uncertainty (about 20\%), this trend has been reproduced for each series of in situ measurements that we carried out. Contraction of the $\mathrm{Nb}-\mathrm{Cl}_{\mathrm{br}}$ distances from $2.54 \AA$ for CYCLE0 (and comparable to 2.57 for solid state $\mathrm{NbCl}_{5}$ ) to about $2.44 \AA$ for CYCLE1,2,3 are also in agreement with this assumption.

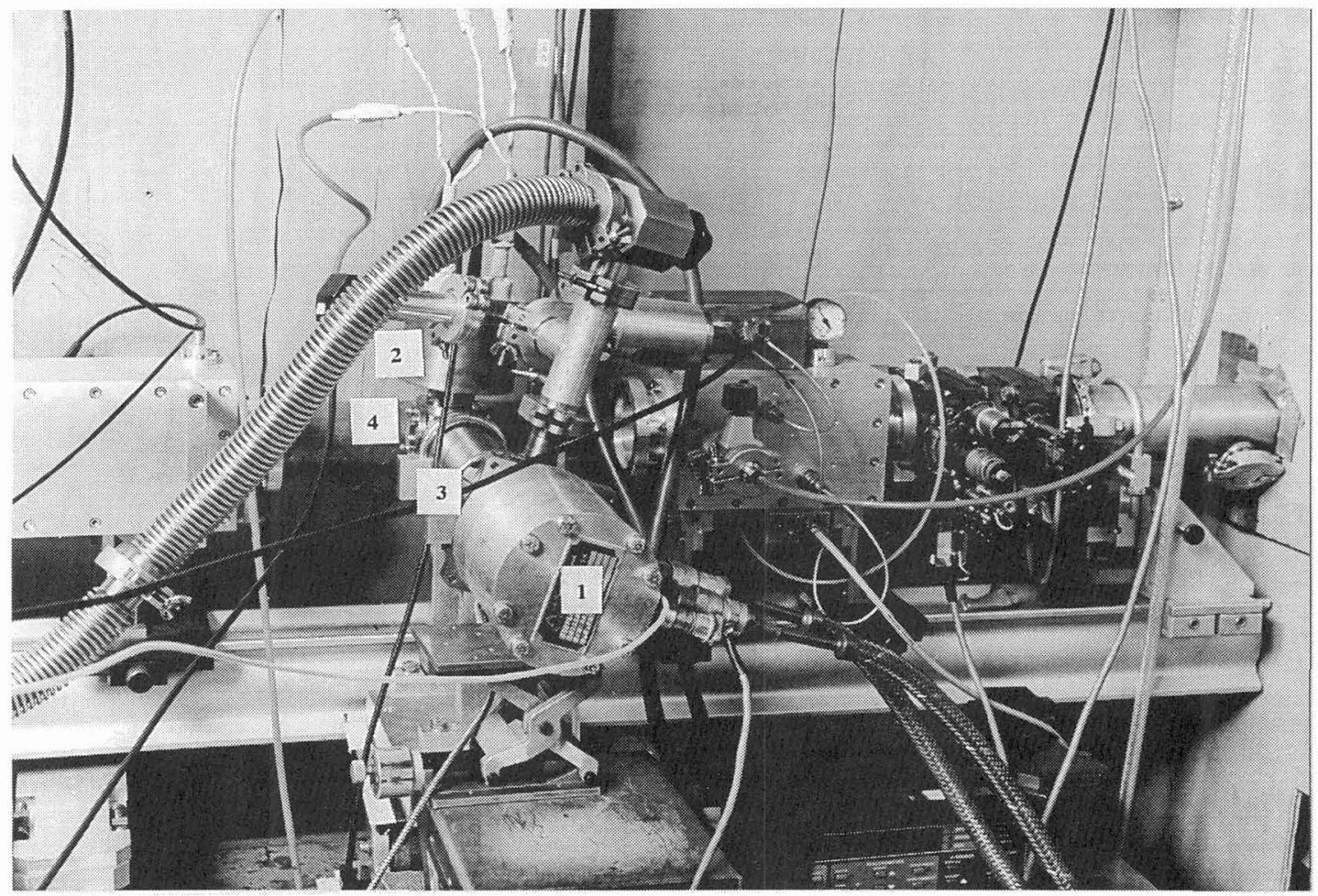

Figure 3: Photograph of the MVS reactor under operating conditions on the D41 beamline at LURE. 1: Helium cryostat. 2: Vaporization fumace. 3 : cryostat shroud. 4: Head of the shroud in which is located the quartz window to hold the pool of $\mathrm{NbCl}_{5}$ solution.

\section{CONCLUSION}

We have demonstrated in this stady the usefulness of metal atom vaporisation techniques to achicve controlled new. solid state structures. The non crystallised materials obtained lead us to mainly use of EXAFS spectroscopy to study the structural evolution of $\mathrm{NbCl}_{5}$ upon $\mathrm{Sm}$ vaporisation. In order to ensure no external alteration of our chemical system, an original in situ reactor was designed and mounted on an $\mathrm{X}$-ray synchrotron beam line. This set-up allowed us to looked at the $\mathrm{NbCl}_{5}$ starting building block condensation, according to a model that was first suggested in previous studies : edge sharing condensation upon samarium vaporisation. 

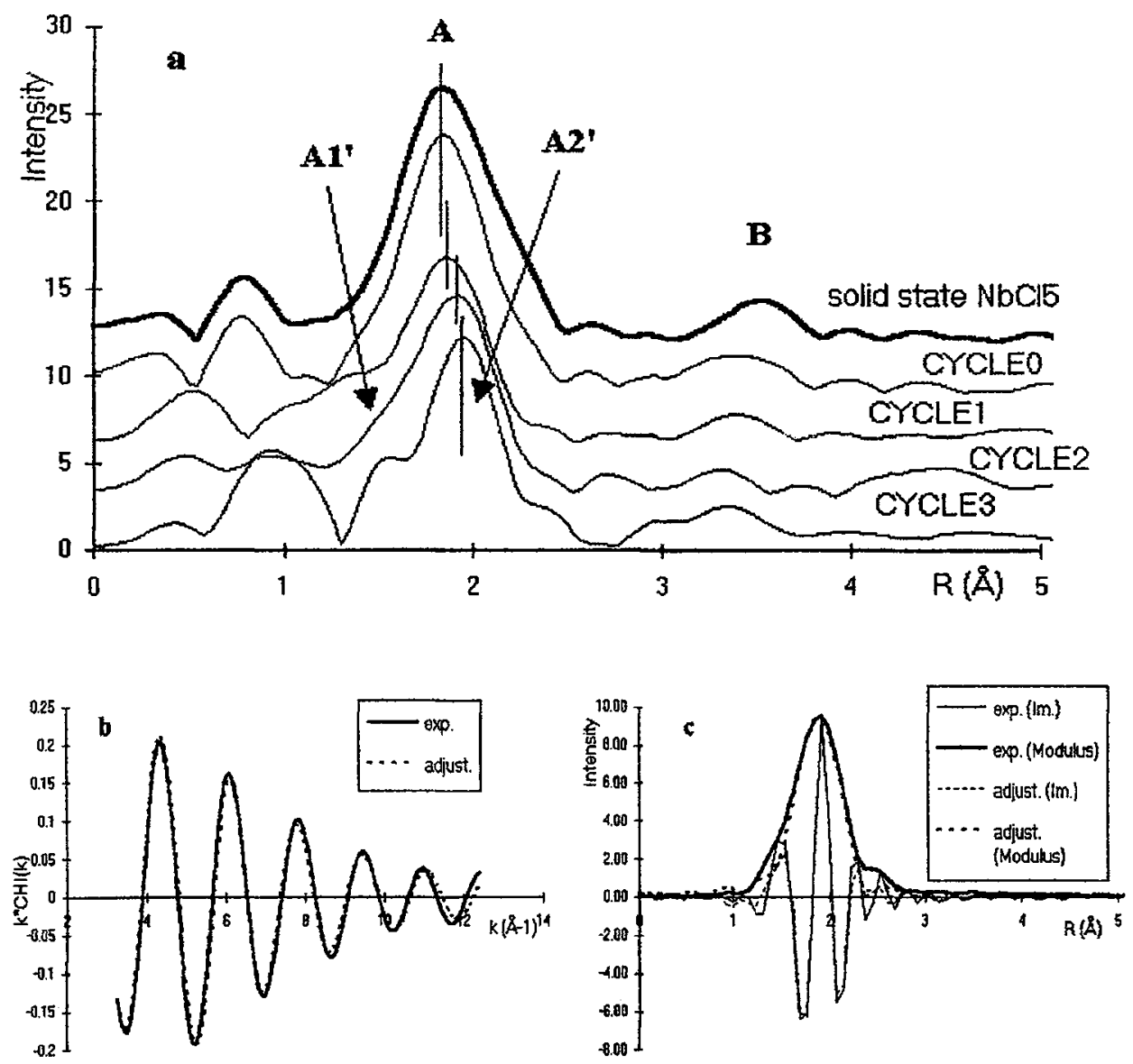

Figure 4: a) Fourier transformation of the EXAFS oscillations of the reaction medium at $130 \mathrm{~K}$ compared to solid state $\mathrm{NbCl}_{5}$ at $77 \mathrm{~K}$; b) Fit of the EXAFS oscillations of CYCLE3 reaction meadium; c) Fit of the FT of the EXAFS oscillations of CYCLE3 reaction meadium.

\section{Acknowledgements}

The authors are very grateful to F. Villain (LURE) and L. Deakin (McGill) for their help during this work. We are also very grateful to the technicians of both laboratories for their indispensable technical competencies. Finally, we would like to thank Pr. M. Sergent for fruitful discussions. 
Table 1. EXAFS best fit parameters of the $\mathrm{Nb}-\mathrm{Cl}$ contributions.

\begin{tabular}{|c|c|c|c|c|c|c|}
\hline sample & $\mathbf{N}$ & $\sigma(\AA)$ & $r(\AA)$ & $\mathrm{Cl}$ type & $\eta(\%)$ & residual \\
\hline $\mathrm{NbCl}_{5}$ & $4.0^{*}$ & 0.05 & $2.27^{*}$ & terminal & & $1.9 \%$ \\
\hline at $77 \mathrm{~K}$ & $2.0^{*}$ & 0.10 & $2.57^{*}$ & bridging & & \\
\hline \multirow[t]{2}{*}{ CYCLEO } & 4.2 & 0.05 & 2.27 & terminal & \multirow[t]{2}{*}{100} & \multirow[t]{2}{*}{$2.5 \%$} \\
\hline & 1.8 & 0.18 & 2.54 & bridging & & \\
\hline \multirow[t]{2}{*}{ CYCLE1 } & 2.5 & 0.01 & 2.34 & terminal & \multirow[t]{2}{*}{75} & \multirow[t]{2}{*}{$2.1 \%$} \\
\hline & 3.5 & 0.07 & 2.44 & bridging & & \\
\hline \multirow[t]{2}{*}{ CYCLE2 } & 2.4 & 0.09 & 2.33 & terminal & \multirow[t]{2}{*}{80} & \multirow[t]{2}{*}{$2.5 \%$} \\
\hline & 3.7 & 0.07 & 2.44 & bridging & & \\
\hline \multirow[t]{2}{*}{ CYCLE3 } & 1.8 & 0.08 & 2.35 & \multirow{2}{*}{$\begin{array}{l}\text { terminal } \\
\text { bridging }\end{array}$} & \multirow[t]{2}{*}{90} & \multirow[t]{2}{*}{$2.8 \%$} \\
\hline & 4.2 & 0.10 & 2.43 & & & \\
\hline
\end{tabular}

*means that these values are fixed to the cristallographic data [6].

N: number of neighbours; $\sigma$ : Debye-Waller factor

The two layers corresponding to $\mathrm{NbCl}_{5}$ are not reported in the CYCLE1,2,3 adjustment. They correspond to the parameters defined with the adjustment of CYCLE0, with weight 100- $\eta$.

\section{References:}

[1] Den Auwer C., Andrews M. P., Briois V., Cartier dit Moulin C., Dexpert H., J. Chim. Phys. 92 (1995) 1084-1092.

[2] Den Auwer C., Andrews M. P., Briois V., Cartier dit Moulin C., Dexpert H., submitted to. Chemistry of Materials.

[3] Klabunde K. J., Reactive intermediates, in Abramovich Ed. Plenum Press, New York, 1980) vol. 1.

[4] Blackborow J. R. and Young D., Metal vapour synthesis in organometallic chemistry (Springer Verlag, Berlin, 1979).

[5] Michalowicz A., Thesis: Méthodes et programmes d'analyse des spectres d'absorption des rayons X (EXAFS). Applications à l'étude de l'ordre local et du désordre cristallin dans les matériaux inorganiques (Université Paris Val de Marne, Marne la Vallée, France, 1990).

[6] Cotton F. A., Kibala P. A., Matusy M., Sandor R. B. W., Acta Crystallogr. C47 (1991) 2435-2437. 